\title{
Wilson's disease presenting as acute hepatic failure: A case report
}

\author{
Rashid $\mathrm{HO}^{1}$, Das $\mathrm{DC}^{2}$, Mahtab MA ${ }^{3}$, Begum $\mathrm{R}^{4}$, Hossain $\mathrm{SMS}^{5}$, Roy PP ${ }^{6}$, Rahman $\mathrm{S}^{7}$
}

\section{Introduction}

Wilson disease (WD) was first described in 1912 by Kinnear Wilson as "progressive lenticular degeneration," a familial, lethal neurological disease accompanied by chronic liver disease leading to cirrhosis. ${ }^{1} \mathrm{~J}$ N Cumings first elucidated the link between copper and Wilson's disease in $1948 .^{2}$ This is an inherited disorder of copper metabolism manifesting typically as hepatic disease in children and as neurological disease in older children and young adults. Copper overload in WD occurs due to reduced biliary excretion of copper. ATP7B gene was identified as the defective gene causing the disease by three independent teams in 1993. ${ }^{3-5}$ ATP7B protein is a membrane bound copper transporting P-type ATPase which transports copper out of the hepatocytes into bile for incorporation of copper into ceruloplasmin, which is then secreted into the blood stream. Absent or reduced function of ATP7B protein leads to decreased hepatocellular excretion of copper into bile. This results in hepatic copper accumulation and injury. Eventually, copper is released into

1. Dr Harun Or Rashid, Medical Officer, Department of Hepatology, Bangabandhu Sheikh Mujib Medical University, Dhaka

2. *Dr Dulal Chandra Das, Medical Officer, Department of Hepatology, Bangabandhu Sheikh Mujib Medical University, Dhaka. Email : dulaldas36@gmail.com

3. Dr Mamun Al Mahtab, Associate Professor, Department of Hepatology, Bangabandhu Sheikh Mujib Medical University, Dhaka

4. Dr Rokshana Begum, Department of Hepatology, Bangabandhu Sheikh Mujib Medical University, Dhaka

5. Dr Sharker Mohammad Shahadat Hossain, Department of Hepatology, Bangabandhu Sheikh Mujib Medical University, Dhaka

6. Dr Partho Protim Roy, Department of Hepatology, Bangabandhu Sheikh Mujib Medical University, Dhaka

7. Professor Dr Salimur Rahman, Professor, Department of Hepatology, Bangabandhu Sheikh Mujib Medical University, Dhaka

*For correspondence the bloodstream and deposited in other organs, notably the brain, kidneys, and cornea. WD presents with liver disease more often in children and younger adult patients than in older adults. Symptoms at any age are frequently nonspecific.

\section{Case report}

A 35 years old man presented to us with features of prodrome includes abdominal pain, nausea $\&$ vomiting for twelve days and altered sleep pattern for three days. He had no history of intake of any drug with known hepatotoxicity in the last three months and was non-alcoholic. His parents were consanguineously married and neither he nor his three siblings had history of any hepatic or neurological manifestation suggesting Wilson's disease

On physical examination the patient was severely icteric,all neurological exam was normal except flapping tremor and had tender hepatomegaly.

On investigation his total serum bilirubin was $25 \mathrm{mg} / \mathrm{dL}$, SGPT 1779 U/L, SGOT 256 U/L, Alkaline phosphatase $129 \mathrm{U} / \mathrm{L}$, INR 1.65, serum albumin $3.5 \mathrm{gm} / \mathrm{dL}$. His haemoglobin was $13 \mathrm{mg} / \mathrm{dL}$, platelet count $2,40,000 / \mathrm{cmm}$ and peripheral blood film showed nonspecific morphology. Haemoglobin electrophoresis was done and showed to be normal.

He was found to be negative for anti-HEV IgM, anti-HAV IgM, HBsAg, anti-HBc IgM, anti-HCV, anti-CMV IgM, anti-Dengue IgM and anti-HSV 1 (IgM) \& anti-HSV 2 (IgM ) by ELISA. He was also found to be negative for ANA, ASMA, anti-LKM1, AMA (M2) antibodies by ELISA and his serum iron profile was normal. On further investigation his urinary copper was $188.48 \mathrm{microgm} / 24 \mathrm{~h}$. His serum ceruloplasmin was near the lower end of normal reference $(31 \mathrm{mg} / \mathrm{dL})$ and he had bilateral $\mathrm{KF}$ ring on slit lamp ophthalmic examination.

Abdominal ultrasonography revealed hepatomegaly with poor echo pattern and marked periportal echogenicities. Gallbladder was contracted even after overnight fasting. All these findings were consistent with fulminant hepatic failure. Upper gastrointestinal tract (GIT) endoscopy was normal. His siblings were screened for Wilson's disease with 
serum ceruloplasmin, urinary copper and slit lamp examination for KF ring, but all were found to be normal.

The patient was put on copper chelation therapy with oral penicillamine along with supportive treatment. It was started at $500 \mathrm{mg}$ penicillamine daily in two divided doses which were gradually raised to $1000 \mathrm{mg}$ daily also in two divided doses. His blood count, urine routine examination and liver function tests were routinely done and neurological functions carefully monitored. The patient underwent eventless recovery and is currently on maintenance copper chelation therapy with $1000 \mathrm{mg}$ penicillamine daily in two divided doses.

\section{Discussion}

WD occurs worldwide with an average prevalence of around 30 affected individuals per million population. ${ }^{6}$ Wilson's disease is rare but important genetic disease in young patient. It is a well-recognized and often encountered in our clinical practice. Several aspect of current case make it worth reporting.

Firstly, Wilson's disease usually present in children and young adult, although presentation up to 70 years has been reported. Secondly, Wilson's disease usually manifests as a chronic disease in its hepatic and/or neurological form(s). Acute presentation of the disease is infrequent and increasingly diagnosed in children younger than 5 years old, with atypical findings as acute liver failure. ${ }^{7}$ Current case is middle aged with presentation as acute liver failure. Thirdly, unlike in chronic Wilson's disease, in its acute form, serum ceruloplasmin is expected not to be low, but rather to be normal or raised as in our case, since ceruloplasmin is an acute phase protein. This can make the diagnosis of Wilson's disease difficult. Fourthly, acute Wilson's disease may be accompanied by 'Coomb's test negative'haemolyticanaemia, due to excessive lysis of red blood cells following sudden rise in copper in blood. Our patient fortunately did not have this complaint. Fifthly, a slit-lamp examination by an experienced observer is required to identify Kayser-Fleischer rings in most patients. They are not entirely specific for WD, because they may be found in patients with chronic cholestatic diseases ${ }^{8-10}$. In our case bilateral $\mathrm{KF}$ ring are present due to WD as chronic cholestasis excluded. Finally, it is expected that parents of Wilson's disease will be consanguineously married and one or more siblings will also be affected. In our case, though parents are consanguineously married, siblings are not affected.

Diagnosis of Wilson's diaease depends on its variable presentation and a number of investigations including presence of KF ring, high 24hrs urinary copper and normal level of ceruloplasmin as ceruloplasmin is acute phase protein.

It is advisable to reduce consumption of foods high in copper content, like shellfish, nuts, chocolate, mushrooms and organ meats. Serum copper levels are usually reduced in Wilson's disease, in proportion to reduced serum ceruloplasmin. However free copper level, which is not bound to ceruloplasmin, is high in most patients with Wilson's disease. Urinary copper is a reflection of free copper in the circulation. Measuring urine copper is useful in diagnosis of Wilson's disease and can be used as a measure of monitoring and compliance to therapy. Though dry weight estimation of hepatic copper is the gold standard to diagnose Wilson's disease, low values due to sampling variability can occur in significant hepatic fibrosis and cirrhosis due to Wilson's disease. ${ }^{11}$ High values can occur in chronic cholestatic liver disorders.

Drug therapy aimed to reduce/abolish symptoms, prevent development of permanent liver damage and normalized serum and urinary copper level. Of the drugs used to treat Wilson's disease, penicillamine and trientine mainly act by increasing cupriuresis, while oral zinc mainly acts by inhibiting copper absorption from the intestine ${ }^{12}$. Recommended first line regime is treatment with copper chelators like penicillamine or trientine to normalize copper levels in the body, followed by maintenance treatment with lower dose of copper chelators or zinc. Transition from the initial high dose chelator therapy to maintenance therapy is made once patient is clinicallywell, has normal liver function tests, and 24 hour urine copper become on treatment. Treatment needs to be continued lifelong. Measuring 24 hour urine copper excretion while on treatment is useful to monitor compliance.

Ammonium tetrathiomolybdate appears to be useful as initial therapy in neurological Wilson's diseasehowever experience is very limited ${ }^{13}$. Though it is not necessary in our patient as neurological manifestation due to ate liver failure with encephalopathy not due to WD itself. Antioxidants such as vitamin E may be useful adjuncts to treatment. ${ }^{14}$

Fulminant hepatic failure and in patients with decompensated cirrhosis, due to Wilson's disease non-responsive to medical therapy, liver transplantation is treatment of choice. Following liver transplantation hepatic insufficiency is corrected and neurological manifestations improve in up to $80 \%$ cases $\&$ urvival at 1 year is about $80 \% .{ }^{15}$ 


\section{References}

1. Wilson SAK. Progressive lenticular degeneration: a familial nervous disease associated with cirrhosis of the liver. Brain. 1912; 34:295-507.

2. Cumings JN. The copper and iron content of brainand liver in the normal and inhepatolenticular degeneration. Brain. $1948 ; 71: 410-5$.

3. Bull PC, Thomas GR. Rommens JM, Forbes JR. Cox OW. The Wilson disease geneis aputative coppertransporting P-type ATPasesimll-tothe Menkesgene. Nat Genet. 1993 ; 5(4):327- 37.

4. Tanzi RE, Petrukhin K, Chernov I, PellequerJL, Wasco $\mathrm{W}$, RossB et al. The Wilson disease gene is a copper transporting ATPase with homology to the Menkes disease gene. Nat Genet. 1993 ; 5(4):344-50.

5. Yamaguchi Y, Heiny ME, Gitlin JD. Isolation and characterization of a human liver DNA as a candidate gene for Wilson disease. Biochem Biophys Res Commun. 1993;197(1):271 -7.

6. Frydman M. Geneticaspects of Wilson's disease. J Gastroenterol Hepatol. 1990;5:483-90.

7. Kalach N, Seidman EG, Morin C, Rasquin-Weber A, O' ReganS, Laberge JM et al. Acutel iver failure from Wilson's disease in a five year-old child. Can J Gastroenterol. 1993;7:610-12.

8. Fleming CR, Dickson ER, Wahner HW, Hollenhorst RW, McCall JT. Pigmented corneal rings innon-Wilsonian liver disease. Ann Intern Med. 1977;86:285-8.
9. Frommer D, Morris J, Sherlock S, Abrams J, Newman S. Kayser-Fleischer-like rings in patients without Wilson's disease. Gastroenterology. 1977;72:1331-5.

10. Tauber J, Steinert RF. Pseudo-Kayser-Fleischer ring of the cornea asso-ciated with non-Wilsonian liver disease. A case report and literature review. Cornea. 1993;12:74-7.

11. Steindl P, Ferenci P, Dienes HP, Grimm G, Pabinger I, Madl C et al. Wilson's disease in patients presenting with liver disease: a diagnostic challenge. Gastroenterology. 1997; 113(1): 212-8.

12. Ferenci P, Steindl-Munda P, Vogel W, Jessner W, Gschwantler M, Stauber R et al. Diagnostic value of quantitative hepatic copper determination in patients with Wilson's Disease. Clin Gastroenterol Hepatol. 2005; 3(8): 811-8.

13. Brewer GJ, Askari F, Lorincz MT, Carlson M, Schilsky $\mathrm{M}$, Kluin KJ et al. Treatment of Wilsondisease with ammonium tetrathiomolybdate: IV. Comparison oftetrathiomolybdateandtrientine in a double-blind study of treatment the neurologic presentation of Wilsondisease. Arch Neurol. 2006; 63(4): 521-7.

14. Sinha S, Christopher R, Arunodaya GR, Prashanth LK, Gopinath G, Swamy HS et al. Is low serum tocopherol in Wilson's disease a significant symptom? J Neurol Sci. 2005; 228(2):121-23.

15. Sevmis S, Karakayali H, Aliosmanoglu I, Yilmaz U, Ozcay F, Torgay A et al. Liver transplantation for Wilson's disease. Transplant Proc. 2008; 40(1):228-30. 